of this work, it is not because we do not appreciate its good points, which are many and obvious. Should a further edition be called for, we trust the above criticism will be considered helpful. Although confined almost entirely to American birds and the work of American workers, the general principles enunciated hold good for practically all countries, and all interested in the economics of wild birds will find a wealth of material for careful considera. tion. Prof. Henderson's book is a valuable addition to the literature on economic ormithology, and he is to be congratulated on meeting an obvious need.

Walter E. Collinge.

\section{Science and Faith.}

Adventure: the Faith of Science and the Science of Faith. By the Rev. Canon Burnett $\mathrm{H}$. Streeter, Catherine M. Chilcott, John MacMurray, and Dr. Alexander S. Russell. Pp. ix +247. (London: Macmillan and Co., Ltd., 1927.) $7 s .6 d$. net.

$\mathrm{T}$

HE book, Canon Streeter tells us, arose out of a series of informal conferences at which the relations between science and religion were discussed, mainly by the "scientists and philosophers of the post-War generation in Oxford." The essays have, therefore, somewhat of a common viewpoint, and it is a novel and stimulating one. The title is intriguing. We do not as a rule associate the idea of adventure with religion, or very often with science, and books about their relation are apt to be dull and platitudinous. The present volume does escape that reproach, and does treat the question from a new viewpoint.

Dr. A. S. Russell, who writes the first paper, on "The Dynamic of Science," has little difficulty in showing that the spirit of adventure is active in science at the present day, particularly in the physical sciences.

"At the present day," he says, "the student of natural science does not allow himself to be deterred from a theory merely because it appears incredible or incompatible with all that has gone before. To such theories indeed he is attracted. The spirit of adventure is strong in him. During the second half of last century the development of science was away from adventure and towards a form of intellectual pharisaism. All the great principles appeared to have been discovered and correctly formulated, and the scientist was inclined to believe that all that needed to be done, especially in physics, was to improve the petty details. This point of view changed rapidly when it was realised that the details were not petty, but capable of leading to astounding conclusions" (p. 18).
It is the facts themselves that have shaken the old conceptions-the facts discovered by bold and patient experiment. Nature is much more remarkable than our theories or imaginings admit. Dr. Russell writes mainly from the point of view of the physicist, and we miss in the book any equivalent treatment of biology. Or is the spirit of adventure, of revolution, less manifest in this domain?

What of adventure in religion? Mr. MacMurray considers this in a really remarkable essay entitled "Beyond Knowledge," in which he deals in a penetrating way with the relation of 'faith' to 'knowledge.' He rejects the common view that faith is a kind of knowledge-that it is belief opposed to reason, or based upon intuition, or on mystical experience. He considers it to be an attitude of will, a way of acting in the face of uncertainty or ignorance. This is, he maintains, what faith means in the New Testament, and he discovers the same attitude at the root of scientific endeavour.

"Modern science," he writes, "rests upon an attitude of will which meets the impotence of mere thought by a continuous reconstruction through criticism and experiment. This attitude of will, we have argued, is the presupposition of all living knowledge, and we have suggested its identity with faith" (p. 37).

It is action-the experimental and courageous grappling with practical difficulties-that is "beyond knowledge." Purely rational and "careful" thought does not take us very far ; there must be constant testing by experiment, constant adventuring into the yet unknown complexities of Nature. Science and religion are both based upon this attitude of faith, and "Such a life of faith lies beyond knowledge, because it is the transcendent spirit of knowledge, the courageous life of creative adventure" (p. 45).

It is perhaps rather unfair to Mr. MacMurray to attempt to present his point of view in a few sentences. The whole essay, which is closely reasoned and rich in suggestion, must be read. There is much in it open to criticism, but it does present a vital and stimulating point of view,-all the more stimulating if one does not fully agree with it.

The remaining essays in the book take us rather beyond the scope of subjects appropriate for discussion in Nature. There are three theological essays by Canon Streeter, Mr. MacMurray, and Miss Chilcott, and a long article on "Moral Adventure" by Canon Streeter, in which the problems of sex morality are dealt with in a broad and sane, but not very adventurous, way.
E. S. R.

$$
\text { No. } 3047 \text {, VoL. 121] }
$$

